\title{
The Impact of Macroeconomic Environment on Cost Stickiness : Evidence from China
}

\author{
Tingting $\mathrm{Li}^{1}$, Zhenning Zhang ${ }^{2 *}$ \\ ${ }^{12}$ Dalian University of Science and Technology \\ *Corresponding author Email: ninggood@naver.com
}

\begin{abstract}
Macroeconomic factors affect the cost of enterprises. The article uses the data of Chinese listed companies from 2011 to 2019 to verify that Chinese listed companies still have cost stickiness, and at the same time we empirically tests the impact of macroeconomic factors on the cost stickiness of Chinese listed companies from macro-financial management perspective. Our research indicates, under the circumstance that the situation of overall trend of GDP growth rate is declining, and the growth rate of individual years has increased, the company managers ignore the trend of GDP growth rate, fail to make timely adjustments, and blindly maintain excessive idle resources, inhibiting downsizing, leading to a higher level of cost stickiness. Empirical results prove that macroeconomic environmental factors can increase the stickiness of costs. Our research deepens the explanation of cost stickiness from the macro financial management perspective, we make up for the lack of cost stickiness research, enriches the academic literature of macro financial management, and helps Chinese listed companies reduce cost stickiness.
\end{abstract}

Keywords: Cost stickiness, Macroeconomic environment, GDP, Empirical research.

\section{INTRODUCTION}

Cost management and control is an important part of modern enterprise management, and it is also a management area where enterprise managers are minimally disturbed by the outside world and are easy to improve. Traditional cost theory believes that the extent of change in cost is the same as the business volume of a company rises and falls. However, empirical studies on cost management in recent years have proved that costs and expenses are sticky, that is, when the cost of a business changes with changes in business volume, the marginal rate of change is asymmetry in different directions of business volume changes, and when business volume increases The increase in cost is greater than the decrease in cost when the business volume is reduced by the same amount. We use the data of Chinese listed companies to test the existence of cost stickiness, and use a financial perspective to verify whether the macroeconomic environment has an impact on the cost stickiness of enterprises, thereby broadening the perspective of cost management research.

The article focuses on Chinese companies and collects 8,693 company observation samples from 2011 to 2019, and tests the impact of the macroeconomic environment on corporate cost stickiness. Similar to the hypothesis we put forward, corporate managers should pay attention to the growth of GDP. At the same time, we still need to pay attention to the changing trend of GDP growth rate. In summary, macroeconomic environmental factors will lead to an increase in the stickiness of costs.

The contribution of this paper is the explanation of cost stickiness from the macro financial management perspective. The research results show that macroeconomic environmental factors can increase the stickiness costs. The article has deepened the study of cost stickiness from the perspective of macro-financial management and makes up for the lack of research on cost stickiness in China. We enriched and expanded the academic literature in the field of macro-financial management and help Chinese listed companies reduce the cost stickiness.

\section{LITERATURE AND HYPOTHESIS}

The early literature on cost stickiness examines whether costs vary asymmetrically responding to the change in sales [1]. Chinese research results show that 
Chinese listed companies have significant expense stickiness [2]. The analysis of the financial data of listed companies in the coal industry includes the golden period and the low period of the development of the coal industry. The cost stickiness of the coal industry is generally affected by market conditions. The cost stickiness during the golden period is relatively high, and the cost stickiness during the trough period is weak. It can be seen that national policies and macroeconomic conditions have an important impact on cost stickiness [3].

The macroeconomic environment is an important external factor that needs to be considered for the development and survival of enterprises, and it has its own laws of cyclical fluctuations. The change of the macroeconomic environment is almost a systematic risk faced by enterprises in their production and operation. It affects the business strategy of each development stage of the enterprise, and also affects the rise and fall of the enterprise. In the macroeconomic environment, national economic policies not only affect the development speed of the country's economic cycle, but also affect the development direction and strategic positioning of enterprises. The gross domestic product keeps growing and the country is prosperous and developing, but business managers also tend to ignore the changing trend of the growth rate. That is, when sales decline and the situation of overall trend of GDP growth rate declines, but the growth rate of individual years appears to increase, business managers do not adjust costs in time, so cost stickiness will appear; in addition, in the development of the economic situation, underlying companies often have excessive investment, which makes it impossible to adjust long-term investment in time when sales decline, so cost stickiness will increase. Therefore, the hypothesis is put forward: Chinese listed companies have cost stickiness, and the situation of overall trend of GDP growth rate is declining, but the increase in the growth rate of individual years will increase the cost stickiness of enterprises.

Hypothesis 1: Chinese listed companies still have cost stickiness.
Hypothesis 2: Under the situation of overall trend of the growth rate of GDP is declining, the increase in the growth rate of individual years will increase the stickiness of costs.

\section{MODEL, DATA, AND STATISTICS}

\subsection{Model}

The article uses classic methods such as Anderson (2003) to build model (1) to test whether there is cost stickiness in listed companies in China ; we build model (2) on the basis of model 1 to test whether hypothesis 2 is valid or not. Using the natural logarithm model can eliminate the impact of excessive data variance on the regression coefficients by a certain extent, so it has a better explanatory effect on the regression coefficients. The specific basic inspection model is as follows:

$$
\begin{aligned}
\Delta \operatorname{COST}_{\mathrm{i}, \mathrm{t}}=\beta_{0}+\beta_{1} \times \Delta \mathrm{S}_{\mathrm{i}, \mathrm{t}}+\beta_{2} \times \Delta \mathrm{S}_{\mathrm{i}, \mathrm{t}} \times \mathrm{D}_{\mathrm{i}, \mathrm{t}} \\
+ \text { All interaction terms } \mathrm{i}_{\mathrm{i}, \mathrm{t}}+\beta_{\mathrm{c}} \times \text { Controls }_{\mathrm{i}, \mathrm{t}+} \varepsilon_{\mathrm{i}, \mathrm{t}}
\end{aligned}
$$

$\Delta \operatorname{COST}_{\mathrm{i}, \mathrm{t}}=\beta_{0}+\beta_{1} \times \Delta \mathrm{S}_{\mathrm{i}, \mathrm{t}}+\beta_{2} \times \Delta \mathrm{S}_{\mathrm{i}, \mathrm{t}} \times \mathrm{D}_{\mathrm{i}, \mathrm{t}}$ $+\beta_{3} \times \Delta S_{i, t} \times D_{i, t} \times G D P_{i, t}+$ All interaction terms

Where $\triangle \operatorname{COST}_{\mathrm{i}, \mathrm{t}}$ is the natural logarithm of the ratio of SG\&A costs to lagged SG\&A costs for firm $i$ in year $t, \Delta S_{i, t}$ is the natural logarithm of the ratio of sales to lagged sales for firm $i$ in year $t, D_{i, t}$ is a dummy variable

that equals 1 if the sales in year $t$ are lower than one in year $\mathrm{t}-1$, and 0 otherwise. $\mathrm{GDP}_{\mathrm{i}, \mathrm{t}}$ is a dummy variable that equals 1 if the growth rate of GDP in year $t$ are higher than one in year $\mathrm{t}-1$, and 0 otherwise.

We use Table 1 shows definitions of all other variables. Here, following Anderson (2003) [1], Chen (2013) [4] and Yang (2015) [5], we control for three economic factors that may affect the cost stickiness: firm size, FCF ratio, and asset intensity.

Table 1. Definition of Dependent/Independent Variables

\begin{tabular}{|c|l|}
\hline \multicolumn{2}{|l|}{ Dependent Variables } \\
\hline$\Delta$ COST & Natural logarithm of (SG\&A costs/ lagged SG\&A costs) for firm i in year t \\
\hline \multicolumn{1}{|c|}{ Independent Variables } \\
\hline$\Delta S$ & Natural logarithm of (sales / lagged sales) for firm i in year t \\
\hline D & Dummy variable equal to 1 if sales in year t is lower than one in year t-1, and 0 otherwise \\
\hline GDP & $\begin{array}{c}\text { Dummy variable that equals 1 if the growth rate of GDP in year t are higher than one in year t-1, } \\
\text { and 0 otherwise }\end{array}$ \\
\hline SIZE & Natural logarithm of book value of assets of firm i in year t \\
\hline INT & Natural logarithm of book value of assets divided by sales of firm in year t \\
\hline
\end{tabular}


The dummy variable $D_{i, t}$ has a value of 0 when operating income increases, the part of the log-linear model that contains dummy variables when operating income increases is 0 , so $\beta_{1}$ measures the change in total cost to the increase in operating income, that is: Operating income increased by $1 \%$, and total cost increased by $\beta_{1} \%$. The dummy variable $D_{i, t}$ takes 1 when operating income decreases, $\left(\beta_{1}+\beta_{2}\right)$ measures the change of total cost to the decrease of operating income, that is, operating income decreases by $1 \%$, and total cost decreases by $\left(\beta_{1}+\beta_{2}\right) \%$. If the traditional cost morphology model is effective, that is, the cost increases or decreases in proportion to the increase or decrease of the business volume, then $\beta_{2}=0$ and $\beta_{1}=1$. However, if the total cost is sticky, then $\beta_{1}>\beta_{1}+\beta_{2}$ can be further inferred that $\beta_{2}<0$, and $\beta_{2}$ is statistically significant, and the smaller the $\beta_{2}$, the greater the stickiness of the total cost. The model under the situation of hypothesis 2 shows that the dummy variable GDP equals 1 (the growth rate of GDP in year $t$ are higher than one in period year the $\left(\beta_{1}+\beta_{2}+\beta_{3}\right)$ measures the size of cost stickiness under hypothesis 2 , and $\beta_{3}$ measures the degree of impact of macroeconomic factors on the size of stickiness.

\subsection{Data}

The data are drawn from the intersection of the CSMAR databases over the period 2011 to 2019. We Exclude enterprises with default financial indicators from the sample range to obtain a valid sample. As a result, our final sample consists of 8693 firm - year observations.

\subsection{Descriptive Statistics}

Table 2. Descriptive Statistics

\begin{tabular}{|c|c|c|c|c|c|c|}
\hline & $\mathbf{N}$ & Mean & Standard Deviation & Minimum & Median & Maximum \\
\hline $\boldsymbol{\Delta C O S T}$ & 8693 & 0.13 & 0.31 & -1.81 & 0.10 & 4.77 \\
\hline $\boldsymbol{\Delta S}$ & 8693 & 0.28 & 1.09 & -7.16 & 0.22 & 7.34 \\
\hline $\mathbf{D}$ & 8693 & 0.36 & 0.48 & 0.00 & 0.00 & 1.00 \\
\hline GDP & 8693 & 0.13 & 0.34 & 0.00 & 0.00 & 1.00 \\
\hline
\end{tabular}

Note: $\mathrm{N}$ is the number of sample size

The descriptive statistics of the main variables are shown in Table 2.

The average of $\triangle \mathrm{COST}$ is 0.13 , the median is 0.10 and the average of $\Delta \mathrm{S}$ is 0.28 , the median is 0.22 . The distribution of the two main variables is basically symmetrical, with concentrated data distribution and low dispersion. The average number of dummy variable GDP is 0.13 , indicating that $13 \%$ of the GDP growth rate in the data is higher than the previous period, which belongs to the situation of declining trend of the GDP growth rate studied and the increasing growth rate in individual years in our article.

\section{REGRESSION RESULTS}

The model is used to test Hypothesis 1 and Hypothesis 2. The test results of Hypothesis 1 are shown in Table 3 . From the result of Table $3 \beta_{1}$ is 0.070 and $\beta_{2}$ is -0.043 , so $\beta_{1}+\beta_{2}=0.027$. For every $1 \%$ increase in the revenue of Chinese listed companies, the total cost increases by $0.07 \%$. When the main business income decreases by $1 \%$, the main business cost only decreases by $0.027 \%$, and $0.043 \%$ of the total cost cannot be obtained. That is, the total cost has a stickiness of $0.043 \%$. This shows that Chinese listed companies have cost stickiness. We verify hypothesis 1 .

Table 3 Empirical Test Results of Cost Stickiness Still Exist in Chinese Listed Companies

\begin{tabular}{|c|c|c|}
\hline & Estimate & t-stat \\
\hline Intercept & -0.217 & -3.939 \\
\hline$\Delta S$ & $0.070^{\star * *}$ & 16.294 \\
\hline$\Delta$ Si,t $\times$ Di,t & $-0.043^{* * *}$ & -4.321 \\
\hline SIZE & $0.014^{* * *}$ & 5.902 \\
\hline INT & $0.024^{* * *}$ & 4.927 \\
\hline CFO & $0.022^{* * *}$ & 8.921 \\
\hline R2 & \multicolumn{2}{|c|}{0.047} \\
\hline
\end{tabular}


Note: $* * *$, and $* * *$ indicate significance at the $10 \%$, $5 \%$, and $1 \%$ levels.

Table 4 Empirical Test Results of the Impact of Macroeconomic Environment on Enterprise Cost Stickiness

\begin{tabular}{|c|c|c|}
\hline & Estimate & t-stat \\
\hline Intercept & -0.211 & -3.839 \\
\hline$\Delta S$ & $0.070^{\star * *}$ & 16.344 \\
\hline$\Delta \mathrm{S}_{\mathrm{i}, \mathrm{t}} \times \mathrm{D}_{\mathrm{i}, \mathrm{t}}$ & $-0.036^{\star * *}$ & -3.586 \\
\hline$\Delta \mathrm{S}_{\mathrm{i}, \mathrm{t}} \times \mathrm{D}_{\mathrm{i}, \mathrm{t}}$ & $-0.052^{\star * *}$ & -3.439 \\
\hline$\times \mathrm{GDP} \mathrm{i}, \mathrm{t}$ & & \\
\hline $\mathrm{SIZE}$ & $0.014^{* * *}$ & 5.809 \\
\hline $\mathrm{INT}$ & $0.023^{\star * *}$ & 4.796 \\
\hline $\mathrm{CFO}$ & $0.022^{* * *}$ & 8.816 \\
\hline $\mathrm{R}^{2}$ & & 0.048 \\
\hline
\end{tabular}

Note: *,**, and *** indicate significance at the $10 \%$, $5 \%$, and $1 \%$ levels.

The test results of Hypothesis 2 are shown in Table 4. It can be seen from Table 4 that $\beta 1$ is $0.070, \beta 2$ is$0.036, \beta 3$ is -0.032 , so $\beta 1+\beta 2=0.034, \beta 1+\beta 2+$ $\beta 3=-0.018$, when the main business income rises by $1 \%$, the total cost rises $0.070 \%$; when the main business income drops by $1 \%$, the total cost drops by $-0.018 \%$. That is, the main business income fell by $1 \%$, but the total cost increased by $0.018 \%$. This shows that macroeconomic environmental factors will increase the cost stickiness of enterprises, and the test results are very significant. We verify hypothesis 2 .

From a statistical point of view, it can be shown that Chinese listed companies still have cost stickiness, the situation of overall trend of GDP growth rate is decreasing, and the increase in the growth rate of individual years will increase the cost stickiness of enterprises. The test results are consistent with the expected results.

The reasons for Hypothesis 2 can be explained from the following two aspects: On the one hand, the steady growth of the macroeconomic situation will cause corporate managers to ignore changes in the GDP growth rate, and seriously overestimate the future sales performance expectations. When the sales decline, business managers think that the decline in sales is only temporary and will rise rapidly. In order to avoid unnecessary losses due to cost adjustments, costs will not be adjusted in time, which will lead to greater cost stickiness; on the other hand, business managers often ignore changes in growth trends in a macroeconomic environment with steady growth. The phenomenon of over-investment makes managers not unwilling or unable to adjust long-term investment in time when sales decline, so the cost stickiness will increase significantly.

\section{CONCLUSION}

We conduct empirical research on the financial data of listed companies in China, and draw the following conclusions: Chinese listed companies still have cost stickiness, the situation of overall trend of GDP growth rate is declining, and the increase in the growth rate of individual years will increase cost stickiness.

The enlightenment of the research in this paper is the company's cost management decision-making should not only focus on factors such as traditional internal cost management theories, managerial agency conflicts, and managerial psychological characteristics. We should also pay attention to the impact of changes in macroeconomic factors on corporate cost management. Only in this way can we have a more comprehensive grasp of the company's cost decision-making, and improve the effectiveness of cost management in a targeted manner.

The change of enterprise cost is an extremely complicated process. Cost stickiness is affected by a variety of factors. We reveal the impact of the macroeconomic environment on the cost stickiness of enterprises from the perspective of macro-finance, and explain the macroscopic factors of cost stickiness. Other factors of cost stickiness need to be further studied and discussed.

\section{REFERENCES}

[1] Anderson, M., R. Banker, S. Janakiraman, "Are Selling, General and Administrative Costs 'Sticky'?" Journal of Accounting Research 41, 2003, No. 1: 47-63.

[2] Sun Zheng, Liu Ha, The Expense "Stickiness"Behavior of Chinese Listed Companies, Economic Research Journal, 2004, No. 12.

[3] ZHANG Yongmei, MU Wenjuan, "Empirical Study on the Cost Stickiness of Chinese Coal Listed Companies", Journal of Shandong University of Science and Technology, 2016, Vol. 18.

[4] Chen,C.X.,T.Gores, J.Nasev, "Managerial Overconfidence and Cost Stickiness" Working Paper, University of Illinois at UrbanaChampaign,2013.

[5] Yang, D, "Mergers, CEO Hubris and Cost Stickiness", Emerging Markets Finance and Trade, 2015, 51: S46-63. 